\title{
Study on Coordinated Development of Economy and Environment in Baoding
}

\author{
Shu-ting GU ${ }^{1, a,{ }^{*}, \text { Qiao-zhi ZHAO }}{ }^{1, b}$, Rui $\operatorname{CHEN}^{1, c,}$ and Qi HAN ${ }^{1, d}$ \\ ${ }^{1}$ North China Electric Power University, Baoding 071000, China \\ a1872535492@qq.com, ${ }^{\text {b } z h a o q i a o z h i 2006 @ 126 . c o m, ~}$ \\ c2873551329@qq.com, d2051586146@qq.com \\ ${ }^{*}$ Corresponding author
}

Keywords: Baoding; Entropy Method; Coordination Degree.

\begin{abstract}
Based on the data of 113 key national environmental protection cities in 2014, this paper evaluates the economic and environmental development level of Baoding in comparison with other 112 cities First, it established the economic and ecological environment evaluation index system. And then the weight of each index is calculated, the comprehensive evaluation value of Baoding economic system and ecological environment system is obtained, and the coordination degree of Baoding economic environment is obtained through these two comprehensive evaluation values. The results show that the coordination degree in Baoding is a moderate disorder level, ranking 75th in 113 cities. Finally, the paper puts forward the countermeasures to solve the unbalanced development of economic development and ecological environment protection in Baoding.
\end{abstract}

\author{
保定市经济发展与生态环境保护的协调发展研究 \\ 顾舒婷 $1,{ }^{a},{ }^{*}$, 赵巧芝 $2, b$, 陈瑞 ${ }^{3, c}$, 韩琪 $4, d$ \\ 1华北电力大学, 保定, 河北, 中国 \\ a1872535492@qq.com, bzhaoqiaozhi2006@126.com, \\ c2873551329@qq.com, d2051586146@qq.com
}

关键词: 保定市; 熵值法; 协调度

中文摘要. 本文基于 2014 年的 113 个全国环境保护重点城市的相关数据, 将保定市经济与环境 协调发展水平与其他 112 个城市相对比进行评价分析。首先建立了经济与生态环境的评价指标 体系。然后经计算得到了各个指标的权重, 及保定市经济系统与生态环境系统各自的综合评 价值, 并通过这两个综合评价值得到保定市经济环境的协调度。结果显示保定市的协调度属 于中度失调的水平, 在 113 个城市中排名第 75 。最终, 提出解决保定市经济发展与生态环境保 护不协调发展的相关对策。

\section{1. 引言}

伴随着经济的快速的发展, 环境污染问题接踵而至。经济与生态环境协调发展的问题成 为了我们所需解决问题的重中之重。国务院在2007年发布了《国家环境保护 “十一五” 规划》 （以下简称规划），明确了113个城市为环保重点城市，并指出，“十一五”期间，将以北京、 天津、上海等113个环保重点城市和城市群地区的大气污染综合防治为重点, 努力改善城市和 
区域空气环境质量。作为 113 个全国环保重点城市之一的保定市, 自 21 世纪以来, 整体发展可 以说是日新月异，但是在经济社会飞速发展的同时，也出现了一系列亟待解决的环境问题。 本文将就保定市经济与环境协调发展水平与其他的 112 个环境保护重点城市对比进行评价分 析。

\section{2. 数据的选取与评价指标体系的建立}

\section{1 数据指标的确定}

设经济评价系统中的 $n$ 个指标分别为 $X_{1}, X_{2}, X_{3}, \cdots, X_{n}$; 环境评价系统中的 $m$ 个指标分别 为 $Y_{1}, Y_{2}, Y_{3}, \cdots, Y_{m}$ 。以上指标均为正数。本文选取了 2014 年全国 113 个重点环境保护城市 (包 括保定）的相关数据为数据样本，查阅各省（市）统计年鉴、《中国环境统计年鉴》和《中 国环境统计公报》等资料。

\section{2 评价指标体系的建立}

本文在对保定市经济与生态环境协调发展水平进行评价时，分别对经济系统和环境系统 选取了10个细化指标进行评价分析。相关指标及具体关系见表 $1:$

表1＼cjkstart保定市经济与生态环境协调发展综合评价指标体系

\begin{tabular}{|c|c|c|c|}
\hline \multirow{20}{*}{$\begin{array}{l}\text { 保定市经济与生 } \\
\text { 态环境协调发展 }\end{array}$} & \multirow{10}{*}{ 经济综合实力评价指标 } & \multirow{3}{*}{ 经济水平 } & GDP \\
\hline & & & 人均 GDP \\
\hline & & & 居民消费价格指数 \\
\hline & & \multirow{2}{*}{ 经济结构 } & 第二产业比重 \\
\hline & & & 第三产业比重 \\
\hline & & \multirow{3}{*}{ 经济活力 } & 人均 GDP 增长率 \\
\hline & & & 第三产业产值增长率 \\
\hline & & & 工业总产值增长率 \\
\hline & & \multirow{2}{*}{ 经济效益 } & 人均财政收入 \\
\hline & & & 农村居民人均纯收入 \\
\hline & \multirow{10}{*}{ 环境综合实力评价指标 } & \multirow{4}{*}{ 环境污染 } & 工业废水排放强度 \\
\hline & & & 工业废气排放强度 \\
\hline & & & 工业固废产生强度 \\
\hline & & & 工业 $\mathrm{SO}_{2}$ 排放强度 \\
\hline & & \multirow{4}{*}{ 环境治理投入 } & 工业废水治理费用 \\
\hline & & & 工业废气治理费用 \\
\hline & & & 废气治理设施数 \\
\hline & & & 工业固废综合利用率 \\
\hline & & \multirow{2}{*}{ 环境产出 } & 细颗粒物 (PM2.5) 年平均浓度 \\
\hline & & & 空气质量达到及好于二级的天数 \\
\hline
\end{tabular}

资料来源：作者自制。

\section{3. 模型的构建}

\section{1 各项评价指标权重的确定}

我们通常用熵值来判断某个指标的离散程度，指标的离散程度越大，熵值也越大，则该 指标对综合评价的影响也越大, 所赋予的权重也就越大。因此, 本文采用熵值法 ${ }^{[1]}$ 给各个指 标赋权重。其具体赋权重步骤如下:

3.1.1 评价指标数据标准化 
本文采用将指标变量进行标准化的方法, 消除各指标数据因量纲不同所带来的差异。设 $p_{i j}$ 为第 $i$ 年份第 $j$ 个指标标准化后的值, $v_{i j}$ 为第 $i$ 年份第 $j$ 个指标的值, $t$ 为评价的年数, $k$ 为指 标的数量。

我们将指标分为正向指标和负向指标, 分别对其进行标准化, 则 $p_{i j}$ 分别为:

$$
p_{i j}=\frac{v_{i j}-\min _{1 \leq i \leq t}\left(v_{i j}\right)}{\max _{1 \leq i \leq t}\left(v_{i j}\right)-\min _{1 \leq i \leq t}\left(v_{i j}\right)}, \quad p_{i j}=\frac{\max _{1 \leq i \leq t}\left(v_{i j}\right)-v_{i j}}{\max _{1 \leq i \leq t}\left(v_{i j}\right)-\min _{1 \leq i \leq t}\left(v_{i j}\right)}
$$

3.1 .2 计算各指标的熵值

设 $e_{i j}$ 为第 $j$ 个指标的熵值, 根据熵值的计算公式, 则 $e_{i j}$ 为:

$$
e_{i j}=-\frac{1}{\ln } \sum_{t}^{t} f_{i j} \ln f_{i j}(i=1,2, \cdots, t ; j=1,2, \cdots, k)
$$

3.1 .3 计算各指标的权重

记第 $j$ 个指标的熵权为 $w_{j}$, 根据熵权的计算公式, 则 $w_{j}$ 为:

$$
w_{j}=\frac{1-e_{j}}{\sum_{j=1}^{k}\left(1-e_{j}\right)}(j=1,2, \cdots, k)
$$

3.1.4 计算系统的综合评价值

设 $r_{j}$ 为第 $i$ 个年份的综合评价得分, 则综合评价函数为:

$$
r_{i}=\sum_{j=1}^{k} p_{i j} \times w_{j}
$$

\section{2 协调度的计算}

本文采用协调度对保定市经济发展与生态环境之间的关系进行研究，找出二者之间所存 在的联系与矛盾。协调度可以衡量在不同发展阶段中各地区经济系统与生态环境系统之间协 调状况, 其在一定程度上反映区域的可持续发展状况。在文中用 “ $D$ ” 来表示, 计算公式为:

$$
D=\left\{\frac{4 * f(x) * g(y)}{[f(x)+g(y)]^{2}}\right\}^{\alpha}
$$

其中: $\alpha$ 为调节系数, 且 $\alpha$ 的取值大于等于 2 , 本文为了便于操作与计算, 规定 $\alpha$ 取值为 2 。 $f(x)$ 表示保定市经济系统的综合得分, $g(y)$ 表示保定市生态环境系统的综合得分。

协调度 $D$ 的取值范围为 $[0,1]$, 协调度越大越协调, 1 为最佳协调状态。据此, 本文设定协 调度的等级及其划分标准情况见表 2 :

表2 协调度分类表

\begin{tabular}{c|c|c|c|c|c}
\hline 协调度 & $0-0.09$ & $0.10-0.19$ & $0.20-0.29$ & $0.30-0.39$ & $0.40-0.49$ \\
\hline 协调类型 & 极度失调 & 严重失调 & 中度失调 & 轻度失调 & 濒临失调 \\
协调度 & $0.50-0.59$ & $0.60-0.69$ & $0.70-0.79$ & $0.80-0.89$ & $0.90-1$ \\
协调类型 & 勉强协调 & 初级协调 & 中级协调 & 良好协调 & 优质协调 \\
\hline
\end{tabular}

数据来源: 潘慧玲. 江苏生态环境与经济协调发展研究[D].江南大学,2012。[2] 


\section{4. 模型的求解与分析}

\section{1 各项评价指标权重的计算}

根据上述熵值法求权重的步骤, 求得经济系统和生态环境系统各指标的权重, 所得结果 见表3:

表3＼cjkstart保定市经济系统与生态环境系统的指标权重

\begin{tabular}{c|c|c|c}
\hline 经济系统指标 & 权重 & 生态环境系统指标 & 权重 \\
\hline GDP & 0.218344 & 工业废水排放强度 & 0.118663 \\
人均GDP & 0.115257 & 工业废气排放强度 & 0.083174 \\
居民消费价格指数 & 0.258566 & 工业固废产生强度 & 0.054630 \\
第二产业比重 & 0.029418 & 工业SO排放强度 & 0.043897 \\
第三产业比重 & 0.068913 & 工业废水治理费用 & 0.033152 \\
人均GDP增长率 & 0.019362 & 工业废气治理费用 & 0.068877 \\
第三产业产值增长率 & 0.009331 & 废气治理设施数 & 0.098333 \\
工业总产值增长率 & 0.008997 & 工业固废综合利用率 & 0.143871 \\
人均财政收入 & 0.181951 & 细颗粒物(PM2.5)年平均浓度 & 0.119019 \\
农村居民人均纯收入 & 0.089860 & 空气质量达到及好于二级的天数 & 0.236384 \\
\hline
\end{tabular}

数据来源：作者根据熵值法的相关公式, 自行计算而得。

\section{2 经济与生态环境系统的综合评价值的计算}

利用上文的系统综合评价函数，计算得出经济系统和生态环境系统的综合得分。下表为 前五名、后五名环境保护重点城市的经济系统和生态环境系统得分, 结果见表4:

表4 全国前五、后五环境保护重点城市经济系统和生态环境系统得分

\begin{tabular}{ccc|ccc}
\hline & 经济系统 & & \multicolumn{3}{c}{ 生态环境系统 } \\
\hline 排名 & 城市 & 得分 & 排名 & 城市 & 得分 \\
1 & 北京 & 2.692551 & 1 & 海口 & 6.139459 \\
2 & 深圳 & 2.597377 & 2 & 北海 & 6.063962 \\
3 & 石嘴山 & 2.128929 & 3 & 湛江 & 5.945488 \\
4 & 杭州 & 2.080379 & 4 & 汕头 & 5.928702 \\
5 & 宁波 & 2.074273 & 5 & 厦门 & 5.882958 \\
109 & 曲靖 & 0.484137 & 109 & 保定 & 2.552806 \\
110 & 齐齐哈尔 & 0.456287 & 110 & 邯単 & 2.52563 \\
111 & 渭南 & 0.455444 & 111 & 石家庄 & 2.501542 \\
112 & 保定 & 0.437527 & 112 & 唐山 & 2.277726 \\
113 & 南充 & 0.433745 & 113 & 阳泉 & 2.224472 \\
\hline
\end{tabular}

数据来源: 作者自行计算得出。

从表4中, 我们可以清晰的看出这十个城市得分相差很大。在经济方面, 北京、深圳等地 处于前列, 北京经济系统综合得分最高, 为 2.693 , 南充的得分最低, 为 0.434 。而保定的得分 为 0.438 , 处于 113 个全国重点城市中倒数第二的位置, 这说明保定市的经济发展极为缓慢。 在环境方面, 海口、北海等地排名较为靠前, 海口处于第一的位置, 得分为 6.139 , 阳泉得分 最低, 为 2.224 。保定处于倒数第五的位置, 得分为 2.553 , 可以看出保定市的环境状况也是比 较恶劣的。

\section{3 协调度及协调度类型}

将全国113个环境保护重点城市的协调度进行排名和等级分类, 下表为前五名、后五名以 及保定市的协调度以及协调类型，见表5: 
表5＼cjkstart环境保护重点城市经济发展与生态环境系统协调度

\begin{tabular}{c|c|c|c}
\hline 排名 & 城市 & 协调度 & 协调类型 \\
\hline 1 & 北京 & 0.969998 & 优质协调 \\
2 & 畄博 & 0.869964 & 良好协调 \\
3 & 郑州 & 0.846024 & 良好协调 \\
4 & 天津 & 0.780361 & 中级协调 \\
5 & 杭州 & 0.779468 & 中级协调 \\
75 & 保定 & 0.249625 & 中度失调 \\
109 & 沾州 & 0.114720 & 严重失调 \\
110 & 绵阳 & 0.113764 & 严重失调 \\
111 & 齐齐哈尔 & 0.089395 & 极度失调 \\
112 & 南充 & 0.087338 & 极度失调 \\
113 & 曲靖 & 0.084921 & 极度失调 \\
\hline
\end{tabular}

数据来源: 查找资料所得。

由表5看出, 北京、淄博、郑州、天津与杭州协调度较高, 排名前五; 曲靖、南充、齐齐 哈尔、绵阳与沪州协调度较低, 排名后五。保定市的协调度值在 113 个城市内排名 75 , 得分为 0.25 , 属于0.2 0.29的范围之内, 是中度失调。也就是说, 保定市的经济发展与生态环境发展 两者之间发展不协调, 并且其协调程度在 113 个环境保护重点城市的协调程度中属于中下游水 平。因此, 保定市的经济发展与生态环境发展两者的协调发展还有待提高, 存在追赶其他城 市协调度的空间。

\section{5. 总结}

根据对保定市经济环境的协调发展分析，可以看出保定市经济与生态环境这两者之间的 协调程度不容乐观, 结果显示经济与生态环境的协调度类型属于中度失调。本文针对保定市 的具体情况, 提出以下对策。经济层面, 一方面进行产业结构升级, 将第二产业逐渐向第三 产业转移, 减少第二产业对化石资源的消耗; 另一方面对各企业环境污染方面实施一定的惩 罚措施, 将环保与经济挂钩, 能更有效地提高大家对环境保护的意识。环境层面, 一方面改 变以煤炭为主的能源结构, 加快发展可再生能源, 发展绿色经济; 另一方面, 增加绿化面积, 植树造林, 改善环境。政府层面, 河北雄安新区作为新的经济特区, 其生态环境问题是值得 政府极大重视的一个问题, 政府应会拨款专治其环境问题, 保定也会因此受益, 能够在不牺 牲本地经济发展的前提下, 治理环境, 使得经济与环境相匹配。相信经过不断的努力, 保定 市经济与生态环境的协调问题会得到改善, 并能赶超其他城市。

\section{致谢}

本文为保定市社科基金项目《保定市经济发展与生态环境保护的协同发展对策研究》 (2015BD0108)的阶段性成果之一。

\section{References}

[1] HeyouZhang.Study on the coordinated development of ecological environment and economy in TianjinCity [D].TianjinUniversity of Finance and Economics, 2015.

[2] Huiling Pan. Study on Coordinated Development of Eco - environment and Economy in JiangsuProvince [D]. JiangnanUniversity, 2012. 